\title{
Neisseria gonorrhoeae, Beta-lactamase Positive Measurement
}

National Cancer Institute

\section{Source}

National Cancer Institute. Neisseria gonorrhoeae, Beta-lactamase Positive

Measurement. NCI Thesaurus. Code C161398.

The determination of the amount of beta-lactamase positive Neisseria gonorrhoeae present in a sample. 